\title{
doispontos:
}

\section{Exogamia em Freud e Lévi-Strauss:}

\section{algumas aproximações}

\author{
Janaína Namba \\ Universidade Federal de São Carlos
}

Resumo: A exogamia e a interdição do incesto são colocadas como um problema, tanto para a antropologia estrutural em Lévi-Strauss quanto para a psicanálise freudiana. Para o antropólogo, a interdição é uma regra fundamental, ainda que negativa, da lei da exogamia. Já para Freud, a exogamia é consequência de um ato primordial, o assassinato do pai da horda. Para ambos, a exogamia inaugura a passagem da natureza para a cultura. Esse texto mostra, no que diz respeito à exogamia e à interdição do incesto, algumas possíveis convergências entre essas duas teorias que tradicionalmente divergem entre si.

Palavras-chave: exogamia; antropologia estrutural; mito; psicanálise; repressão; incesto.

\begin{abstract}
For the structural anthropology in Lévi-Strauss theory and for freudian psychoanalysis, the exogamy and the interdiction of incest are poses as a problem. For the anthropologist the interdiction is a fundamental rule, although negative of the exogamic law. For Freud, the exogamy is a consequence of a primal act, the murder of the father of primitive hord. For both, the exogamy inaugure the course from nature to the culture. This text shows, relative on exogamy and the interdiction of the incest, some possible convergences in these theories that are tradictionnaly in disaccord.
\end{abstract}

KeyWords: Exogamy; Structural Anthropology; Myth; Psychoanalysis; Repression; Incest.

Dentre uma série de seminários interdisciplinares proferidos no Collège de France entre os anos de 1974 e 1975, que tinham como tema $A$ identidade, o psicanalista André Green apresentou o trabalho intitulado "Átomo do parentesco e relações edipianas" (GREEN, 1983, p. 81). Nesse trabalho, Green relaciona psicanálise e antropologia social a partir dos conceitos de inconsciente psicanalítico e da concepção de átomo de parentesco para a antropologia estrutural que fora explorado anteriormente em "Análise estrutural em linguística e em antropologia”, de Lévi-Strauss (Antropologia estrutural). Segundo o psicanalista francês,

\begin{abstract}
primeiramente, o inconsciente, o ego inconsciente, arruína a ideia de uma unidade do ego e consequentemente a própria noção de indivíduo. [...] O que gostaria de notar é que a noção de indivíduo não é um conceito para Freud. Segundo ponto: o ego não é o sujeito e, terceiro ponto, enfim: o sujeito só pode se definir na perspectiva psicanalítica pela sua relação com seus genitores (GREEN, 1983, p. 83).
\end{abstract}

Ainda que essa citação não nos mostre muito a interface entre a antropologia e a psicanálise, ela nos indica certo modo de abordá-la. Para a psicanálise freudiana não há uma unidade egoica, ou seja, uma ideia de unidade do indivíduo, do eu. Ao contrário, o psiquismo é dividido. Para a teoria psicanalítica freudiana, o psiquismo divide-se a partir do recalque originário, que, por sua vez, determina diferentes modos de funcionamento: inconsciente e consciente. Ainda que essa diferenciação se inicie prematuramente, "uma 
divisão clara e definitiva do conteúdo dos dois sistemas, como regra geral, não se estabelece até a puberdade" (FREUD, 2004b, p. 192).

No segundo ponto, Green afirma que a noção de indivíduo não é um conceito e que o ego não é sujeito, isto é, que o ego não compõe o indivíduo por inteiro.

No entanto, podemos encontrar essa expressão na $31^{\underline{a}}$ Conferência, $A$ decomposição da personalidade psíquica. Mas cabe notar que Freud o faz em contraposição à noção de objeto:

o ego é certamente o sujeito mais genuíno. Mas como poderia se tornar objeto? Sem dúvida isso é possível. O ego pode tomar-se a si mesmo como toma a outros objetos, observar-se e criticar-se, e Deus sabe quantas coisas pode empreender consigo próprio. Para isso, uma parte do ego contrapõe-se ao restante. O ego é então cindível, se divide no curso de muitas de suas funções, ao menos provisoriamente (FREUD, 2004c, p. 54).

O ego, na visão freudiana, é passível de divisão, mas pode se reorganizar e logo se unificar. Ele irá compor uma unidade, uma instância psíquica, desde uma unificação pulsional e de eleições de objeto. Como decorrência da formação dessa instância psíquica, tem-se ainda sua própria separação tanto da instância das paixões, o id, quanto da instância que mede como sendo seu ideal, o superego.

De acordo com a teoria psicanalítica freudiana, o desenvolvimento psíquico ocorre juntamente com o desenvolvimento pulsional sexual, e, desde 1905, nos Três ensaios..., Freud supõe uma sexualidade infantil que se origina e se descola das necessidades vitais. A partir dessas moções sexuais infantis, que têm suas metas redirecionadas (pela repressão e pela sublimação) para fins não sexuais, são erigidas importantes construções pessoais e da cultura, bem como delas decorrem a responsabilidade pela normalidade psíquica do indivíduo adulto.

Nas fases pré-genitais, oral e sádico-anal, as moções sexuais se encontram apoiadas em outras funções vitais, ou orgânicas, como o sugar e o evacuar, bem como se comportam de maneira auto-erótica, isto é, "buscam e encontram seus objetos no próprio corpo" (FREUD, 2004d, p. 287), portanto, não necessitam de um objeto exterior a si próprio para obter prazer. Já na fase posterior, a de eleição de objeto, há uma unificação dessas pulsões, que são parciais, sob o primado genital que num primeiro momento, durante a infância, não tem função reprodutora, o que acontece apenas posteriormente, na puberdade (cf. FREUD, 2004d, p. 292). Como nos diz Freud,

\footnotetext{
Na vida sexual - o que chamamos de função libidinal - não emerge como algo acabado, tampouco cresce semelhante a si mesma, mas nela se pode observar uma série de fases sucessivas que não apresentam o mesmo aspecto [...] e o ponto de viragem desse desenvolvimento é a subordinação de todas as pulsões parciais sob o primado dos genitais (FREUD, 2004d, p. 299).
}

A subordinação das pulsões parciais ao primado genital inicia-se já na infância, por volta dos dois anos, e há uma convergência das moções sexuais em um único objeto alheio a si mesmo. No entanto, acrescentamos que a escolha desse objeto normalmente se assemelha bastante ao "primeiro objeto da pulsão oral" (FREUD, 2004d, p. 300), o seio materno. E, a partir da eleição de objeto, o seio passa a ser representado pela mãe.

A principal consequência dessa escolha, ou seja, eleger a mãe como objeto de amor, é o desencadeamento do complexo de Édipo e o trabalho psíquico da repressão ou recalque, "que subtrai do saber da criança o conhecimento de uma parte de suas metas sexuais" (FREUD, 2004d, p. 300). O complexo de Édipo que, analogamente, narra a trama da tragédia grega de Sófocles, envolve os desejos dos dois crimes 
de Édipo, o incesto materno e o parricídio, e a repressão recai justamente sobre essas metas sexuais: a de estabelecer uma relação incestuosa com a mãe e de matar o pai.

Uma vez que o desenvolvimento psíquico encontra-se intrincado ao desenvolvimento sexual e, dentre os vínculos sexuais, um dos mais importantes, "o qual ajuda a preparar o modelo de eleição de objeto" e de certo modo reparar a "felicidade perdida", é aquele que surge a partir da nutrição, da mãe ou substituto que alimenta, acaricia, higieniza e nutre o lactente: "não é sem um bom fundamento que o fato da criança mamar no peito de sua mãe se torna paradigmático para todo vínculo de amor" (FREUD, 2004e, p. 203).

Temos, assim, que a própria edificação do aparelho psíquico ocorre desde a separação entre as necessidades e as pulsões, entre as funções vitais e o desejo, isto é, a partir dos cuidados, de higiene e de nutrição, em geral da mãe ou seu substituto, dito de outro modo, da relação com os progenitores ou seus substitutos. Isso porque, ressalta o psicanalista:

não faço aqui, menção ao agente biológico de procriação, mas à ligação de filiação imaginária que une o sujeito aos constituintes do casal, em que ele é o produto da fantasia do desejo vigente de sua vinda ao mundo (GREEN, 1983, p. 82).

Ou seja, para Green, a relação com os pais transcende o vínculo consanguíneo que esses têm com a criança. A relação que precede e propicia o complexo de Édipo na criança é estabelecida a partir da fantasia de desejo dos pais, a criança é ela mesma o objeto escolhido, ou, em termos freudianos, a criança é sua majestade, o bebê. "O narcisismo primário que supomos na criança (...) deve ser observado como a reprodução do narcisismo dos pais, há muito abandonado" (FREUD, 2004b, p. 87). Isso porque, como dissemos anteriormente, a escolha de objeto, ou eleição de objeto, se dá no momento em que há uma unificação das pulsões parciais, período em que a psicanálise denomina também como narcisista.

Freud afirma que uma unidade comparável ao ego não existe desde o início; é necessário que algo se agregue ao auto-erotismo, "uma nova ação psíquica, para que o narcisismo se constitua" (FREUD, 2004b, p. 74). No início não existe uma unidade egoica, pois esta pressupõe o estabelecimento de "relações de objeto" a partir da eleição de um objeto, isto é, a partir do momento em que a libido se unifica. Como explica Luiz Roberto Monzani,

o ego, enquanto fruto de uma diferenciação a partir de um solo original, surge como unidade perante a diversidade do pulsional, que até então funcionou de maneira anárquica e dispersa - ele aparece assim como tal objeto exterior, passível de ser objeto da sexualidade (MONZANI, 1989, p. 245).

Desde a unificação das pulsões e das eleições de objeto, tem-se uma modificação no ego e a formação de um ideal de ego com o qual o ego se mede. "O narcisismo aparece deslocado para esse novo ego ideal que, como o infantil, se encontra em posse de todas as perfeições valiosas" (FREUD, 2004b, p. 91). Sobre esse ideal é que recai o amor sobre si mesmo, aquele de que na infância gozou. O ideal de ego é responsável por manter viva a esperança de recobrar a satisfação que um dia gozou, pois o que ele projeta é o próprio narcisismo infantil, por um processo de idealização. Segundo Freud, a idealização ocorre tanto no deslocamento da libido egoica quanto da libido objetal (cf. FREUD, 2004b), e, como decorrência desse processo que envolve também a sublimação, o criador da psicanálise se pergunta, em 1914, o que irá afirmar em 1923, se não encontraríamos uma instância psíquica que teria como incumbência garantir a satisfação narcísica de um ideal de ego, como $o$ superego.

Dos influxos de investimentos de objeto que se sedimentam no ego, forma-se um caráter, que começou a ser delineado precocemente a partir de identificações. As primeiras identificações ocorrem na mais 
tenra infância; são duradouras e universais. Tais identificações "conduzem à gênese de ideal de ego", pois a primeira e mais importante está, justamente, relacionada à identificação com os progenitores da pré-história pessoal. Uma identificação como essa seria uma forma primitiva de ligação afetiva, que inicialmente não se encontra mediada por investimentos de objeto. Contudo, servirá de modelo para as primeiras eleições de objeto do período sexual mais precoce, no qual o vínculo é feito com os pais ou seus substitutos. De acordo com a teoria freudiana, as primeiras identificações correspondem à pré-história pessoal que envolve o complexo de Édipo.

Nesse complexo, normalmente, o menino identifica-se com o pai, quer crescer e ser como ele em diversos terrenos, o toma como ideal. Já com relação à mãe, toma-a como objeto de desejo sexual. Dada essa configuração, a identificação com o pai pode ganhar "tonalidades hostis", pois o menino deseja substituí-lo, ocupar seu lugar. Seja com o menino, seja com a menina que também deseja ocupar o lugar da mãe, e, portanto, também se identifica com ela, tem-se que esse processo identificatório é ambivalente, no qual coexistem sentimentos hostis, de eliminação, e sentimentos ternos. Além da configuração normalmente encontrada, o complexo de Édipo pode sofrer inversões, e o menino tomar como objeto o pai, "numa atitude mais feminina", assim como a menina identificar-se predominantemente com o pai.

Dessa maneira, é possível diferenciar uma identificação por aquilo que se quer ser de uma escolha de objeto como aquilo que se quer ter, "portanto, a diferença se encontra no fato de a ligação se fazer com o sujeito ou com o objeto do ego. [...] A identificação aspira dar ao próprio ego uma forma semelhante à do outro ego tomado como 'modelo'" (FREUD, 2004h, p. 100), ou, em outros termos, tal como mencionados mais acima, como ideal de ego.

\section{A TROCA E A PROIBIÇÃO DO INCESTO: DA ANTROPOLOGIA ESTRUTURAL À PSICANÁLISE}

Como já dissemos, o ponto de aproximação entre as duas disciplinas seria justamente o da troca, que numa perspectiva antropológica ocorre no plano social, jurídico, religioso e cultural e, numa perspectiva psicanalítica, no plano afetivo.

No capítulo "A troca restrita", de As Estruturas..., Lévi-Strauss menciona que, em certas tribos da Birmânia, o sistema fundamental da reciprocidade é formado com base nas trocas matrimoniais e econômicas. Tem-se que "o método de repartição da carne, utilizado nessa região do mundo, não testemunha uma engenhosidade menor que aquela da repartição das mulheres” (LÉVI-STRAUSS, 1967, p. 39). Isto é, um homem forma sempre uma dupla com uma de suas irmãs, que passa a ser chamada de "irmã emparelhada". Pelo par formado é que se determina o preço da noiva, uma vez que o marido desta já ganha um cunhado. Em contrapartida, dada generosidade dispensada, nas festas o homem tem o papel de elevar o preço exigido pelo casamento das filhas. A distribuição da carne ocorre dentro dos limites do grupo que se liga por parentesco. Para o casal descrito antes, a cabeça do búfalo é dada aos parentes mais próximos e as articulações (dos membros), aos parentes mais distantes. O que nos mostra, além de uma relação hierárquica, regras de distribuição que, mesmo não sendo formalmente do mesmo tipo que aquelas que determinam o preço da noiva, se encontram organicamente ligadas entre si (experiência dos cunhados).

Lévi-Strauss também se refere aos Thonga, da África Oriental, para quem, além da maioria dos parentes, o chefe e aquele que ajudou a levar o animal têm direito a uma parte da carne, de modo que a repartição feita em praça pública da vila tem a finalidade de distinguir os que comem dos que não comem a carne, e, portanto, no interior da família, a autoridade repousa, certamente, sobre "a posse e o controle da 
nutrição" (RICHARDS apud LÉVI-STRAUSS, 1967, p. 42). Nesse capítulo, faz a seguinte observação a respeito da nutrição e das relações matrimoniais:

\begin{abstract}
Nós estamos, sem dúvida, mais sensíveis após alguns anos ao valor dramático de situações dessa ordem; não saberíamos, em todo caso, salvaguardar o leitor eventualmente inclinado a lhes admirar na perspectiva de nossa cultura tradicional, que se apraz em opor o patético do amor infeliz e o cômico da barriga cheia. Na imensa maioria das sociedades humanas, os dois problemas são colocados no mesmo plano, pois, num e noutro domínio, a natureza deixa o homem na própria presença do risco: o sortilégio do homem satisfeito oferece o mesmo valor emotivo, $\mathrm{e}$ pode servir de pretexto à mesma expressão lírica que o homem amado. A experiência primitiva confirma alhures a continuidade entre as sensações orgânicas e as experiências espirituais. A nutrição é toda impregnada de signos e perigos. O sentimento de "calor" poder ser um denominador comum dos estados, para nós, tão diferentes quanto a cólera, o amor ou a saciedade. Essa última, por sua vez, entrava as comunicações com o mundo sobrenatural. Para admitir a assimilação das mulheres às comodidades, por um lado, escasseadas e, por outro, essenciais à vida do grupo, não é necessário evocar o vocabulário matrimonial da Grande Rússia, onde o noivo é chamado de "mercador" e a noiva de "mercadoria". A comparação nos parece menos chocante se conservamos presentes no espírito as análises de A. Richards, que coloca em evidência os sistemas de equivalência psicofisiológicas do pensamento indígena: "a nutrição é a fonte das emoções mais intensas, ela fornece a base de algumas das mais abstratas noções e metáforas do pensamento religioso [...] Para o primitivo, a nutrição pode se tornar o símbolo das experiências espirituais das mais altas e a expressão de relações sociais, as mais essenciais” (LÉVI-STRAUSS, 1967, p. 43).
\end{abstract}

Ao nos convidar a pensarmos como A. Richards, para quem a nutrição é fonte das emoções mais intensas, e também serve como base de noções abstratas e metáforas do pensamento religioso, Lévi-Strauss se aproxima da psicanálise freudiana, na medida em que partimos da nutrição como satisfação de uma função vital que se desdobra na própria sexualidade caracteristicamente humana. Ou seja, a sexualidade, que tem seu desenvolvimento bastante precoce, é derivada de satisfações e frustrações de desejo que edificam o próprio aparelho psíquico pensado por Freud. Da mesma maneira, a exemplo de Richards, para a psicanálise, a nutrição fornece a base tanto para noções abstratas e o desenvolvimento do pensamento por via das pulsões, como é fonte das relações sociais das mais essenciais, como vimos a relação entre a mãe nutriz ou seu substituto.

Para a antropologia estrutural, a nutrição encontra-se intrinsecamente relacionada às trocas matrimoniais e às relações de parentesco. Lévi-Strauss se refere ao universo das regras quando nos mostra a topografia da carne do animal a ser distribuída entre os familiares próximos e distantes, assim como uma determinação das posições familiares dentro da tribo por meio da comida. Dentre os Pigmeus reza o seguinte ditado: quanto mais mulheres existem, há mais o que comer. Isso porque os Pigmeus consideram "as mulheres e as crianças como a parte mais preciosa dos ativos do grupo familiar" (SCHEBESTA apud LÉVI-STRAUSS, p. 1967, p. 45). Há lugares na Polinésia em que o celibato é mais frequente, mas também se constata que nesses lugares a produção alimentar não constitui um problema. Já na Birmânia, a condição do celibato parece ser mais uma consequência do rigor que algumas tribos aplicam às regras de exogamia: "quando a junção prescrita torna-se objeto de uma determinação estrita, o casamento se torna impossível na ausência de um parente que ocupe exatamente a posição requisitada" (LÉVI-STRAUSS, p. 1967, p. 48).

No entanto, conclui ao final desse capítulo, para que a sociedade se constitua como tal, ou seja, como um fato da cultura, é necessária à proibição do incesto uma ação enquanto regra formal. Do contrário, privilégios podem emergir no seio familiar, que por sua vez é colocado no âmbito da natureza: "essa aglomeração natural que é a família”. Apesar de Lévi-Strauss dizer que não há uma anterioridade institucional da família sobre o grupo e nem que cada família tenha um monopólio sobre suas mulheres, num outro lugar (La famille [1956], cf. BELLOUR; CLÉMENT, 1979), afirma que há uma situação paradoxal na formação da família, pois esta depende do casamento para que uma família seja concebida, mas é a própria família que cria os meios legais para que o casamento estabeleça, entre elas, uma aliança. 
Ao partirmos do casamento no texto $A$ familia, de Lévi-Strauss, tem-se que o casamento não representa, na maior parte dos casos, a satisfação do "instinto sexual". Isto é, o casamento é uma instituição que não regulamenta as relações sexuais, mas que coloca pessoas de diferentes sexos numa situação de dependência social e econômica recíproca, pois acaba por promover uma divisão do trabalho entre os sexos (BELLOUR; CLÉMENT, 1979, p. 118). Isso porque o casamento, que é uma relação global de troca, não se estabelece entre um homem e uma mulher onde cada um recebe alguma coisa, ele envolve uma relação entre dois grupos, em que cada um deles é o objeto de troca e não como pares entre os quais eles estavam ligados. Ou seja, há, a partir do casamento, a abertura de um ciclo de reciprocidade que envolve, na verdade, um ciclo ainda mais vasto, pois acaba por penhorar a união de um homem e de uma mulher, cuja filha ou irmã se casa com algum homem (possível), que por sua vez tem uma irmã etc. (cf. LÉVI-STRAUSS, p. 1967, p. 135).

Dessa maneira, retornamos para a posição paradoxal que nos coloca o casamento com relação à formação da família. Mas, para além do paradoxo, devemos nos atentar à situação de aliança. Os casamentos são regidos pela proibição do incesto, e, como consequência disso, é estabelecida uma dependência recíproca entre as famílias, "que lhes força a engendrar novas famílias em vista de se perpetuar" (BELLOUR; CLÉMENT, 1979, p. 118). O etnólogo observa, portanto, que:

Uma família não saberia existir sem sociedade, o que quer dizer, sem uma pluralidade de famílias prestes a reconhecer que existem outras ligações que a de consanguinidade, e que o processo natural de filiação só pode continuar através do processo natural de aliança (BELLOUR; CLÉMENT, 1979, p. 119).

Processo esse que ocorre por coação, como podemos ver a exemplo de Tylor, por sugestão do próprio Lévi-Strauss: "casar-se fora ou ser morto fora", a propósito de uma especulação, a humanidade talvez tenha aprendido muito cedo a se defender de uma luta selvagem. Para isso é necessário escolher entre famílias biológicas isoladas e justapostas como unidades fechadas, submersas em seus medos, suas raivas e suas ignorâncias e, por conta da proibição do incesto, instituir novos casamentos fora das próprias famílias, consequentemente estabelecer novos laços de afinidade (cf. BELLOUR; CLÉMENT, 1979, p. 120).

Ora, não seria essa justamente a situação proposta por Freud em Totem e tabu (1913), ao conjugar a interpretação psicanalítica do totem e a hipótese darwiniana sobre o estado primordial da sociedade humana?

Após a morte do pai da horda primitiva pela união dos irmãos, fica instituída a proibição do incesto para que nenhum deles tenha novamente o privilégio que um dia tivera o pai e, principalmente, porque aquele que ousar obter novamente o lugar do pai se arrisca a ser assassinado, como ele o fora. Segundo Freud,

Existe [na horda primordial] um pai ciumento e violento que reserva todas as fêmeas para si e expulsa os filhos varões quando crescem, e nada mais. [...] A necessidade sexual não une os homens, mas provoca desavença entre eles. Se os irmãos haviam se unido para avassalar o pai, eram também rivais entre si com relação às mulheres. Cada um haveria de querer tê-las todas para si, como o pai. E se houvesse uma luta de todos contra todos, a nova organização teria sucumbido (FREUD, 2004a, p. 145).

A nova organização, antes referida, envolvia, portanto, uma convivência pacífica entre os irmãos, que renunciavam ao poder, o que lhes garantiria a vida de cada um do grupo, e às mulheres de sua própria tribo/ horda, motivo do assassinato do pai. Instituía-se assim a proibição ao incesto e a necessidade de busca de mulheres fora da tribo, instaurando-se a exogamia.

Da mesma maneira, Lévi-Strauss nas Estruturas... coloca a proibição do incesto como "regra de obediência geral" que tem como fundamento a igualdade entre os homens no que se refere à busca das mulheres, 
ou seja, não é possível aos homens reivindicar posições paternas ou fraternas, todos ocupam a mesma posição que lhes foi designada pelo grupo e não pela relação familiar (cf. LÉVI-STRAUSS, p. 1967, p. 49).

Podemos entender então porque a proibição do incesto é apresentada como problema por LéviStrauss: primeiramente porque o caráter ambivalente dessa regra retoma o aspecto sagrado da proibição, e, em segundo lugar, pelo fato de ser uma regra social, dada sua natureza de regra, e ao mesmo tempo ser uma regra pré-social, tanto pela sua universalidade quanto pelo tipo de relação a que ela se impõe como norma (LÉVI-STRAUSS, p. 1967, p. 14). Para o etnólogo,

\footnotetext{
A proibição do incesto não é puramente de origem cultural nem puramente de origem natural; assim como também não é uma dosagem de elementos compostos parcialmente emprestados da natureza e parcialmente da cultura. Ela constitui uma atitude fundamental graças à qual, pela qual, mas, sobretudo, na qual, se cumpre a passagem da natureza para a cultura (LÉVI-STRAUSS, p. 1967, p. 29).
}

Essa passagem da natureza para a cultura só é possível, pois enquanto fato da cultura mergulha no seio da natureza e resgata as estruturas simples pertencentes ao mundo animal, incorporando-as à cultura, "impondo sua regra no seio de fenômenos que inicialmente nada dependiam dela" (LÉVI-STRAUSS, p. 1967, p. 29). Ou seja, para Lévi-Strauss, a ausência de regras marca uma configuração natural, de modo que a regra viria a mudar o padrão das relações entre os sexos: "a natureza já opera, por ela mesma, segundo um duplo ritmo de receber e doar que se traduz na oposição entre o casamento e a filiação" (LÉVISTRAUSS, p. 1967, p. 35). Em outras palavras, o padrão de relação entre os sexos na natureza baseia-se na consanguinidade, ou hereditariedade e, a partir do momento em que se estabelece a regra da proibição do incesto, um homem não pode esposar parentes próximos, como irmã ou filha, devendo renunciá-las a outros homens (DUMONT, 1997, p. 117), ${ }^{1}$ estabelecendo assim relações de aliança que antes eram feitas completamente ao acaso (LÉVI-STRAUSS, p. 1967, p. 36). Isto é, antes do estabelecimento da regra de interdição, o que havia era uma escolha aleatória do parceiro sexual, de modo que era possível esposar pessoas que pertenciam à mesma linhagem consanguínea, isto é, mãe, filha ou irmã, primas próximas, bem como alguém distante, pertencente a outra linhagem, ou, ainda, a um outro grupo. A consequência disso era a manutenção de relações consanguíneas, ou o estabelecimento de relações de aliança entre grupos que ocorriam aleatoriamente, ainda que não fossem consideradas como tal.

Segundo Dumont, em Grupos de filiação e aliança de casamento (1997), para Lévi-Strauss a aliança de casamento é uma teoria restrita, isto é, que envolve apenas primos cruzados bilaterais, ou seja, uma troca bilateral (filha do tio materno ou da tia paterna) que se encontra dentro de uma teoria mais geral, que se pode chamar de teoria estrutural, ou teoria estruturalista de parentesco centrada numa interpretação estrutural da proibição do incesto. Isto é, ainda que a interdição do incesto seja uma "expressão negativa" e parcial de uma lei de troca universal, do princípio universal de reciprocidade, é ela que instaura uma relação de alianças entre famílias, quer dizer, inaugura as relações de alianças sociais (DUMONT, 1997, p. 117). Isso quer dizer que para a antropologia o universo das regras é visto sob a ótica das relações sociais. Nas palavras de Lévi-Strauss,

O fato da regra, visto de maneira inteiramente independente de suas modalidades, constitui, com efeito, a própria excelência da proibição do incesto. Pois a natureza abandona a aliança ao acaso e à arbitrariedade, de tal modo que se torna impossível à cultura não introduzir uma ordem, seja qual for sua natureza. O papel primordial da cultura é garantir a existência do grupo como grupo, e, portanto, substituir nesse domínio, como em todos os outros, a organização ao acaso. A proibição do incesto constitui uma certa forma - ou ainda, formas muito diversas - de intervenção. Mas antes de qualquer coisa ela é a Intervenção (LÉVI-STRAUSS, p. 1967, p. 38). 
Ou ainda, segundo Keck, em Lévi-Strauss, uma introdução (2011), "não é porque há uma interdição que a proibição do incesto é uma regra, mas ela é a regra mínima na qual é instaurada a interdição e da qual se tornam possíveis, por sua vez, todas as regras positivas" (KECK, 2011, p. 90). De modo que a característica universal da proibição do incesto não encerra um valor em si mesmo, ao contrário, a universalidade seria justamente uma forma vazia que permite a constituição de valores diversos. Ou seja, para Lévi-Strauss, é a partir de uma intervenção como essa que se torna possível o estabelecimento de alianças baseadas em regras, ou uma ordenação dessa, e não importa sua natureza, o que quer dizer que trocas em geral (não importa de que produto, se comida, objetos fabricados, ou mulheres) são feitas com base numa reciprocidade. As mulheres entram na categoria dos bens como sendo o mais valioso. E é a troca específica de mulheres que determina a exogamia: assim "como a exogamia, a interdição do incesto é uma regra de reciprocidade", sendo que no primeiro caso ela ocorre de maneira "organizada" e no segundo de maneira "inorgânica" (LÉVI-STRAUSS, p. 1967, p. 72). Isto é, na exogamia, os homens renunciam às mulheres proibidas (filha ou irmã) com a condição de que as do vizinho também sejam renunciadas. No entanto, numa sociedade em que há a interdição do incesto, essa renúncia não é explícita nem imediata, como na exogamia, o que vem causar uma reação violenta de uma sociedade lesada. Isso porque a regra não diz exatamente em benefício do que se renuncia, como no caso da exogamia, em que o beneficiário ou mesmo a classe beneficiária é bem delimitada tanto para os receptores quanto para os doadores:

\footnotetext{
A única diferença é, portanto, que na exogamia se exprime a crença de que se deve definir as classes para que uma relação possa se estabelecer entre essas classes, enquanto na proibição do incesto a própria relação é suficiente para definir, a cada instante da vida social, uma multiplicidade complexa e sem fim, é renovada em termos de solidariedade direta ou indiretamente ( LÉVI-STRAUSS, p. 1967, p. 73).
}

Lévi-Strauss considera tanto a exogamia quanto a interdição do incesto como leis de troca e, ainda que esta última seja considerada uma lei negativa, ela encerra em si a determinação de que haverá reciprocidade. $\mathrm{O}$ que nos mostra que uma sociedade regida pela interdição do incesto, mesmo que tenha uma reação violenta por se sentir lesada, considera, dada certa distensão no tempo, a crença e a confiança no outro. Isso porque ao interditar o incesto, a regra impõe uma renúncia a determinado número de mulheres de acordo com cada sociedade e cada costume. Mas essa, por sua vez, "abre uma via para a reivindicação" (LÉVI-STRAUSS, p. 1967, p. 60) de determinado número possível de mulheres. E mesmo que essas reivindicações se desenrolem em conflitos e tensões psicossociais, a renúncia aos privilégios "não requer, necessariamente, a intervenção ou cálculo de uma autoridade: ela só pode ser a resolução de um conflito afetivo[...]" (LÉVI-STRAUSS, p. 1967, p. 49).

\section{A REPRESSÃO ORGÂNICA E A ANTROPOLOGIA}

Seja pela antropologia, seja pela psicanálise, vimos que uma renúncia como essa dificilmente ocorre de maneira espontânea, sem a intervenção de uma autoridade, sem uma coação. A exemplo da horda primordial, teríamos que a organização recém-formada dos irmãos sucumbiria, caso não houvesse se instaurado a proibição do incesto. Ainda que uma renúncia seja necessária, a via da reivindicação se encontra interditada, pois reivindicar uma mulher do próprio grupo implicaria a própria morte.

Poderíamos dizer que, no psiquismo, o conflito afetivo pode se resolver ou não, uma vez que a renúncia se coloca no plano sexual. Freud nos diz em 1911, nas Formulações sobre os dois princípios do acontecimento psíquico: 
A substituição do princípio do prazer pelo princípio de realidade, com as consequências psíquicas que dela se seguem, na verdade, não ocorre de uma única vez, nem simultaneamente numa única linha. Pois, enquanto esse desenvolvimento ocorre para as pulsões egoicas, as pulsões sexuais se desprendem dele de maneira muito significativa. As pulsões sexuais primeiramente se comportam de forma autoerótica e encontram satisfação no próprio corpo; não chegam, portanto, a uma situação de frustração, que obrigou a instituir o princípio de realidade. $\mathrm{E}$ quando mais tarde incorrem na fase de escolha de objeto, esse processo experimenta prontamente uma prolongada interrupção por obra do período de latência que posterga até a puberdade o desenvolvimento sexual. Esses dois fatores - auto-erotismo e período de latência - têm como consequência que a pulsão sexual fica suspensa em sua expressão psíquica e permanece mais tempo sob o império do princípio do prazer, do qual, em muitas pessoas, jamais pode ser subtraído (FREUD, 2004f, p. 227).

A partir do trecho acima observa-se que, apesar da própria instauração do princípio de realidade, as pulsões sexuais, que se descolaram das necessidades vitais, contornam, seja pela via autoerótica, seja pela suspensão de suas metas sexuais durante o período de latência, o mundo exterior como possibilidade de frustração. Elas seguem a via do princípio do prazer, na qual nenhuma renúncia se torna necessária. Se sucumbirem ao império do prazer por toda a vida, o conflito se torna patológico, ou em termos psicanalíticos, tem-se uma solução de compromisso feita no interior do aparelho psíquico.

A suposição freudiana sobre a imposição do princípio de realidade, quanto à cultura, é de que a bipedestação seria responsável pela instauração da repressão orgânica, ou do momento em que o homem, ao adotar a postura vertical, tornaria visíveis os órgãos genitais que até então se encontravam encobertos por uma postura predominantemente horizontal e, desse modo, passaria a ter vergonha de expô-los, pois passariam a ser uma estimulação constante. Esse processo estaria intimamente ligado ao deslocamento da atenção, antes voltada para as sensações olfativas, devido à periodicidade do ciclo menstrual, para as sensações visuais. O que antes era fonte de excitação visual como ânus e boca deixa de sê-lo, assim como as próprias sensações internas provenientes dessas regiões, que antes serviam de estímulo, já não contribuem com a libido agora liberada dos "genuínos órgãos sexuais" (carta 75, in: FREUD, 2003, p. 311). A principal consequência da adoção da bipedestação, que ocorre em função do afastamento do solo, de uma possível atrofia do sentido do olfato quando comparado à visão e de uma repressão da vida sexual, seria justamente o "início fatal do processo de cultura [...] do ser humano" (FREUD, 2004g, p. 97).

Temos em comum que a cultura para Freud, assim como para Lévi-Strauss, é tomada no sentido em que a vida humana se eleva e se distingue da vida animal. Esse processo se deve, diz Freud, "por um lado, a todo saber e poder-fazer que o homem adquiriu para governar as forças da natureza, e, por outro, compreende todas as normas necessárias para regular os vínculos recíprocos entre os homens" (FREUD, 2004g, p. 6).

Deste modo, a partir da adoção da posição ereta fundar-se-ia uma família primitiva ou, como antes fora referida em Totem e tabu, a horda primitiva. Isso porque o homem deixaria de ter um comportamento de "hóspede", cíclico, para substituí-lo por um comportamento de permanência, de conservação dos objetos sexuais junto a si, de modo que nessa família primitiva já encontraríamos "um traço essencial da cultura” (FREUD, 2004g, p. 6). Uma característica essencial dessa família primitiva seria a coesão entre seus membros e um isolamento do grupo incapaz de aceitar "estrangeiros", isso a caracterizava como uma horda endogâmica. Mas, como vimos, nessa horda primordial havia um pai violento que reservava todos os membros femininos para si e expulsava os filhos varões assim que cresciam, e, num determinado momento, esse pai da horda fora assassinado pelos próprios filhos homens (FREUD, 2004a, p. 142). Com a morte do pai, instaurou-se a proibição do incesto e consequentemente a exogamia (num sentido lato), que tanto Freud como Lévi-Strauss colocaram como fato concomitante ao totemismo.

Freud, apesar de dizer que uma horda primordial nunca existiu, sugere que existam algumas tribos primitivas, dispostas como essas hordas e que possuem uma "liga dos varões composta por membros de 
direitos iguais e submetidos a restrições do sistema totêmico hereditário" (FREUD, 2004a, p. 143). A conquista desses direitos só existiu como consequência desse assassinato promovido pelos filhos expulsos, bem como pelo fato de eles terem devorado o próprio pai. Tais atos de assassinar e devorar são celebrados e podem ser tomados como uma "primeira festa da humanidade". Devorar o pai da horda numa festa como esta é também consumar um processo de identificação com ele, uma vez que os filhos se apropriam de parte de sua força. Essa festa "seria a repetição e celebração daquela façanha memorável e criminosa que dera início a tantas outras coisas, como as organizações sociais, as limitações éticas e a religião" (FREUD, 2004a, p. 144).

Ao falar do horror ao incesto, Freud exemplifica, com uma tribo australiana, a organização de regras éticas num povo "primitivo". Tais regras envolvem justamente a regulamentação dos vínculos sexuais estabelecidos dentro da tribo, "ou seja, impuseram um alto grau de restrição a suas pulsões sexuais" (FREUD, 2004a, p. 12) com o intuito de evitar relações sexuais incestuosas.

Poderíamos dizer então que, do ponto de vista da psicanálise, a proibição do incesto também marca a entrada na cultura por um processo repressivo originário, ou a "repressão orgânica", pelo fato de exigir uma renúncia pulsional. Renúncia individual absolutamente necessária para a sobrevivência da horda. Assim como para a antropologia estrutural estaríamos diante de uma regra que restringe a satisfação do indivíduo para que se configure a vida social.

Se, por um lado, Lévi-Strauss afirma que a proibição do incesto envolve um processo em que a natureza ultrapassa-se a si mesma, por outro ela indica que "uma estrutura de um novo tipo e mais complexa se forma e se superpõe, ao se integrar às estruturas mais simples da vida psíquica” (LÉVI-STRAUSS, 1967, p. 29). Ela ultrapassa-se a si mesma na medida em que modifica a relação natural existente na vida animal. Ao modificar as relações naturais pela imposição de uma regra, acaba por agregar "uma estrutura de um novo tipo", inevitavelmente mais complexa à medida que abrange as relações que passam a ser culturais e não apenas previamente estabelecidas pela natureza.

Assim como para a antropologia forma-se uma estrutura de um novo tipo e mais complexa, para a psicanálise é possível pensar nessa estrutura como a própria organização do clã após o parricídio. Os irmãos têm direitos iguais, ou, ainda, não têm direitos sobre as mulheres do próprio clã. Instaura-se a proibição do incesto e as mulheres devem ser buscadas fora do clã, de modo que novas relações entre clãs devem ser estabelecidas.

O casamento em si, para a antropologia estrutural, é "um reencontro dramático entre a natureza e a cultura, entre aliança e parentesco", pois aí se encontra uma substituição do amor parental pelo amor conjugal, numa espécie de reencontro e confusão de amores que um hino hindu de casamento ilustra: "quem deu a noiva? A quem ela foi dada? $\mathrm{O}$ amor a deu e o amor a recebeu. $\mathrm{O}$ amor preenche o oceano. Com amor eu a aceito. Amor, esse que te pertence". O momento do matrimônio é aquele em que as posições sociais são redefinidas, isto é, aqueles que se casam ocupam por sua vez as posições sociais dos pais, e também eles serão doadores de filhos, como o são os pais. E nesse sentido, Lévi-Strauss considera isso como uma reedição do incesto, "ao menos como um incesto social" (1967, p. 561). 


\section{REFERÊNCIAS BIBLIOGRÁFICAS}

BELLOUR, R.; CLÉMENT, C. (1979). Textes de et sur Claude Lévi-Strauss. Paris : Gallimard.

DUMONT, L. (1997). Lévi-Strauss: les structures élémentaires in Groupe de filiation et alliance de mariage. Paris: Gallimard.

FREUD, S. (2004a). Tótem y tabú y otras obras (1913-1914). Vol. XIII. Buenos Aires: Amorrortu Editores.

(2004b). Contributión a la historia Del movimiento psicoanalitico, trabajos sobre metapsicologia y otras obras (1914-1916). Vol. XIV. Buenos Aires: Amorrortu Editores.

(2004c). Nuevas conferencias de introducción al psicoanálisis y otras obras (1932-1936). Vol. XXII. Buenos Aires: Amorrortu Editores.

(2004d). Conferencias de introducción al psicoanálisis (1916-1917). Vol. XVI. Buenos Aires: Amorrortu Editores.

(2004e). Fragmento de análisis de un caso de histeria, Tres ensayos de teoría sexual y otras obras (1901-1905). Vol. VII. Buenos Aires: Amorrortu Editores.

(2004f). Sobre un caso de paranoia descrito autobiográficamente (Schreber), trabajos sobre técnica psicoanalítica y otras obras (1911-1913). Vol. XII. Buenos Aires: Amorrortu Editores.

(2003). Publicaciones prepsicoanaliticas y manuscristos inéditos en vida de Freud (1886-1899). Vol. I. Buenos Aires: Amorrortu Editores.

(2004g). El porvenir de una ilusión, El malestar en la cultura y otras obras (1927-1931). Vol. XXI. Buenos Aires: Amorrortu Editores.

(2004h). Psicologia de las masas. In: Más allá del principio del placer, Psicologia de las masas y

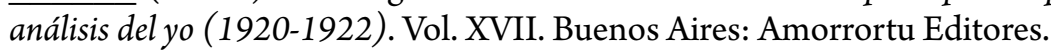

GREEN, A. (1983). L’atome de la Parente. In: Seminaires de Claude Lévi-Strauss: L’ identité. Paris: PUF.

KECK, F. (2011). Claude Lévi-Strauss, une introduction. Paris: Agora.

LÉVI-STRAUSS, C. (1967). Les structures élémentaires de la paranté. Paris: Mouton \& Co.

MONZANI, L. R. (1989). Freud, o movimento de um pensamento. Campinas: Ed. da Unicamp.

\section{NOTAS}

1. Cf. Estruturas elementares ..., prefácio da segunda edição.

2. Freud usa o termo primitivo para designar uma população primordial, muito antiga, e não por achar que exista uma hierarquia de culturas. Cf: ROUDINESCO, E. De près et de loin: Claude Lévi-Strauss et la psychanalyse; Critique Claude Lévi-Strauss, 620/621, Janvier/février, 1999. 